\title{
Correction to: Spatial distribution of heavy metals and their potential sources in the soil of Yellow River Delta: a traditional oil field in China
}

\author{
Xiongyi Miao $\cdot$ Yupei Hao $\cdot$ Fawang Zhang $\cdot$ Shengzhang Zou \\ Siyuan Ye $\cdot$ Zhouqing Xie
}

Published online: 7 February 2019

(C) Springer Nature B.V. 2019

Correction to: Environ Geochem Health

https://doi.org/10.1007/s10653-018-0234-5

In the original publication of the article, the sixth author name "Zhouqing Xie" has been misspelt. The

The original article can be found online at https://doi.org/10.1007/s10653-018-0234-5.

X. Miao $\cdot$ Z. Xie $(\bowtie)$

Institute of Polar Environment, School of Earth and Space Sciences, University of Science and Technology of China, Hefei 230026, China

e-mail: zqxie@ustc.edu.cn

X. Miao

e-mail: miaoxy@karst.ac.cn

\section{S. Ye $(\bowtie)$}

Key Laboratory of Coastal Wetlands Biogeosciences, China Geologic Survey, Qingdao Institute of Marine Geology and Laboratory for Marine Geology, Qingdao National Laboratory for Marine Science and Technology, Qingdao 266071, China

e-mail: ye_syuan@sina.com

Y. Hao $\cdot$ F. Zhang $\cdot$ S. Zou

Key Laboratory of Karst Dynamics, MNR\&GZAR, Institute of Karst Geology, CAGS, Guilin 541004, China correct name is given in this correction. The original version of this article was revised.

Publisher's Note Springer Nature remains neutral with regard to jurisdictional claims in published maps and institutional affiliations. 